\title{
A LEGITIMAÇÃO DO SILÊNCIO NO COTIDIANO DA MULHER NEGRA BRASILEIRA A PARTIR DO FILME BENDITO FRUTO.
}

\author{
Juliana Silva Santos ${ }^{1}$ - FALE/UFMG
}

\section{1-INTRODUÇÃO}

A realização deste trabalho ${ }^{2}$ é fruto de reflexões feitas a partir do grupo de pesquisa sobre as representações do feminino no cinema brasileiro contemporâneo, sob o olhar da Análise do Discurso. Para tanto, o grupo buscou pensar o cinema em relação ao envoltório sócio-discursivo acerca da mulher e, este texto, especificamente, carrega o desafio de falar sobre a mulher negra a partir da representação cinematográfica da personagem Maria ${ }^{3}$, no filme Bendito Fruto ${ }^{4}$ (Brasil, 2005). O objetivo foi levantar algumas das possíveis raízes históricas de sua posição atual de desigualdade silenciada e mantida pelo discurso ${ }^{5}$,tendo como mote a figura dessa personagem. Entende-se nesse texto que, fazer um percurso teórico sobre as mulheres significa, de algum modo, sair do silêncio em que elas estavam confinadas, como apontado pela historiadora Michelle PERROT (2007). Um dos objetivos da pesquisa foi traçar considerações de viés crítico sobre o cinema, deslocando-o da posição de entretenimento. Para isso, um dos primeiros pontos que cabe ser levantado diz

\footnotetext{
${ }^{1}$ Graduanda do $7^{\circ}$ período do curso de Letras da Universidade Federal de Minas Gerais. Voluntária do grupo de pesquisa sobre "As Representações do Feminino no Cinema Brasileiro contemporâneo sob o olhar da Análise do Discurso".

${ }^{2}$ Este texto parte do texto final de uma pesquisa realizada em 2009. O texto em sua versão integral será publicado posteriormente.

${ }^{3}$ Personagem interpretada pela atriz Zezeh Barbosa.

${ }^{4}$ Filme dirigido por Sérgio Goldenberg.

${ }^{5}$ O termo "discurso" nesse trabalho se faz entendido segundo o que a Análise do Discurso de linha Francesa denomina como o encadeamento "transfrásico" (NAGAMINE 2007), articulando os campos linguístico e social.
} 
respeito à dificuldade de se falar sobre o cinema e sua função social sem se pensar em uma condição de produção que objetiva, salvo as devidas gradações, a uma adesão de público e a uma difusão ideológica. A partir desse pensamento, julga-se que o cinema enquanto veículo difusor de ideologias ${ }^{6}$, não é em si neutro. A afirmativa não é nova. Segundo o estudioso do cinema, Graeme Turner, tem havido muitas tentativas na contemporaneidade, no sentido de se entender o cinema e sua relação com a ideologia. Para o autor, essas investidas têm ocorrido sob vários olhares, sendo uma delas, o cinema e a cultura de massa (TURNER, 1988), categoria em que a produção eleita, Bendito Fruto se enquadra. Nesta película, procurou-se destacar elementos que seriam capazes de embasar aquilo que na definição de Pierre Bourdieu (2003) seria caracterizado como uma "eternização das estruturas da divisão sexual e dos princípios de divisão correspondentes". Estruturas que são traduzidas em valores, e que construídos a partir de uma aparente homogeneidade, norteiam a superfície das representações, fazendo com que elas se figurem ausentes de rupturas, acarretando assim, o silenciamento definido por ORLANDI (1995), como resultado final da análise.

De início, é válido esclarecer sobre o termo que encabeça o grupo de pesquisa na qual esse artigo se insere: representação. Nesse estudo, o termo se fará entendido como um sistema lingüístico e cultural de imagens construídas sobre o real, imagens que, por sua vez, estariam relacionadas à busca de formas apropriadas de tornar a denominação de "real" presente, tendo, portanto um sentido arbitrário e intimamente ligado às relações de poder. (SILVA; 91).

A partir de algumas situações do filme, buscou-se investigar algumas marcas que consubstanciam, tendo as teorias da Analise do Discurso de Escola Francesa ${ }^{7}$ como base teórica, as lacunas do não-dito, entendidas aqui como silenciamento ou política do silêncio $^{8}$, a partir das posições discursivas ocupadas pela personagem Maria e também pelos sujeitos em seu entorno. Nessas situações, tentou-se associar uma reflexão

\footnotetext{
${ }^{6}$ Cf. BRANDÃO, 2007. Utilizamos o termo ideologia nesse segundo a concepção de Althusser (1970).

7 A partir desse ponto, usaremos a sigla "AD" sempre que nos referirmos à Análise do Discurso.

${ }^{8} \mathrm{Cf}$. ORLANDI, 1995. O silêncio como categoria discursiva será discutido no decorrer da análise.
} 
acerca da memória discursiva ${ }^{9}$ correlata a um determinado imaginário veiculado sobre a mulher negra a partir da personagem.

\section{2- O OLHAR DA RETOMADA}

A construção de filmes ancorados num suposto modelo de realidade, não é nada incomum se nos remontamos ao contexto de produção cinematográfica brasileira desde a década de 90, e do qual Bendito Fruto é certamente tributário. A produção de Goldenberg é de 2005 e se enquadra nos momentos finais de um contexto cinematográfico denominado Cinema da Retomada. Esta fase é também marcada por obras cujo apelo ao público tem a presença de personalidades televisivas, em que é clara a presença do padrão Globo Filmes. Ainda que não seja produzido diretamente pela Globo, o estilo de produção de Goldenberg carrega o legado da emissora, em produção, financiamento e divulgação. Outra característica forte do padrão Globo e que se observa na película em questão, diz respeito à utilização de sujeitos de grande participação em telenovelas. Relacionando o filme à reprodução de comportamentos por meio da ideologia, a atuação de sujeitos conhecidos do grande público e não de outros atores desconhecidos por ele não é arbitrária. A escolha por personalidades famosas no elenco é vista como elemento de forte influência para o autoreconhecimento e identificação por parte do público, fazendo com que os sujeitos possam de algum modo "se ver" através das personagens.

\footnotetext{
${ }^{9} \mathrm{Cf}$. NAGAMINE, 2007. O termo será desenvolvido no decorrer da análise.
} 


\section{3-O SILENCIAMENTO E SUAS RAÍZES: O REFERENCIAL TEÓRICO}

\section{1-Discurso, ideologia e memória discursiva: possíveis raízes do silenciamento.}

Para M. Bakhtin, a palavra é intrinsecamente ideológica, considerando-a como um produto de interações sociais das quais submergem diferentes vozes diretamente ligadas a um determinado “local de enunciação" (BRANDÃO 2007). Dessa forma, tem-se que a linguagem enquanto um modo de interação que não é neutro. $O$ discurso nessa perspectiva seria de constituição lacunar, ou seja, permeado por "silêncios" que mantêm a coerência e os aspectos hierárquicos de uma dada organização social. Para a construção desse sentido, a AD postula que o sujeito é de constituição fundamentalmente histórica e sua fala carrega um recorte de representações de si e do outro a quem ele se dirige. Esse recorte histórico em relação a outros discursos já consolidados se faz mais claro a partir da definição de memória discursiva. Para a AD, a memória, quando discutida em relação ao discurso possui características de situações pré-construídas ou que "falam antes", posicionando discursos com a maneira como foram inscritos na língua e na história.

\section{2- A dominação segundo Bourdieu}

Para Pierre Bourdieu (2003), existe uma determinada eternização das estruturas de dominação que faz com que os sujeitos dominados não reflitam sobre elas em nível profundo, de maneira a mantê-las naturalizadas ao longo da história. Nesse sentido, o conceito de habitus de que trata o sociólogo é fundamental. Em linhas gerais, o habitus seria como uma "disposição incorporada, quase postural". Então, os 
indivíduos na sociedade já conhecem as condições de funcionamento do meio no qual se inserem, podendo garantir a estabilidade social e cultural da dominação. Vê-se, portanto, que se trata de um conceito que vai ao encontro da noção de memória discursiva para a $A D$, uma vez que o habitus caracteriza-se sumariamente por um sistema que é consagrado no passado, mas que orienta ações no presente. Ele fornece uma dada compreensão de mundo que naturaliza a dominação por ideologias dominantes e a violência simbólica ${ }^{10}$. Assim:

Produto de um trabalho social de nominação e de inculcação ao término do qual uma identidade social instituída por uma dessas 'linhas de demarcação mística', conhecidas e reconhecidas por todos, que o mundo social desenha, inscreve-se em uma natureza biológica e se torna um habitus, lei social incorporada". (BOURDIEU 2003:63-34).

Tanto a dominação de gênero - e acrescentamos ainda a questão racial -, estariam numa determinada "ordem das coisas", dispensando qualquer tipo de justificação (BOURDIEU, 2003). O autor desenvolve essa noção de ordem a partir da ausência de marcação do gênero masculino, visto como neutro, em oposição ao feminino, extremamente detalhado lingüisticamente, tanto pelo lado subjetivo como por adjetivação física. O mesmo acontece ao tratarmos do quesito raça: subrepresentada nos contextos midiáticos e literários, a mulher negra é muitas vezes construída a partir de elementos que não deixem dúvida sobre sua cor de pele. No âmbito da mídia, não raro encontramos o uso de estereótipos que causem associação direta a um determinado imaginário discursivo. Assim, a mulher escrava, empregada doméstica ou a mulata sensual, são modelos de representação já consagrados. A mulher negra nesse sentido não fala, mas é falada, uma vez que ela não é significada fora de determinados padrões de identidade nacional, definidores de um ideal de representação construído discursivamente. A conseqüência é muitas vezes a

\footnotetext{
${ }^{10} \mathrm{O}$ conceito de violência simbólica é tributário da noção de poder simbólico de que trata Bourdieu em sua obra "O poder simbólico", em que o conceito é definido como "poder invisível o qual só pode ser exercido com a cumplicidade daqueles que não querem saber que lhe estão sujeitos ou mesmo que 0 exercem".(BOURDIEU, 1989: 07, 08).
} 
incorporação do habitus, que pode causar impactos negativos na auto-estima e identidade dos sujeitos.

Pode-se pensar ainda em uma relação ideológica entre a memória discursiva e àquilo que estudos das relações raciais nomeiam normatividade branca ou Branquitude, ou seja, a determinação de um padrão branco para as atitudes dos sujeitos. Intimamente ligado às relações de poder, esse modelo, normativo, tem raízes que remontam à virada do século XIX para o XX, através da chamada ideologia de branqueamento que via na miscigenação uma estratégia "branquear" a população brasileira, estimando que assim o desaparecimento dos negros se daria de maneira natural e em no mínimo cem anos. A perpetuação e naturalização simbólica de dominação às questões de gênero e raça passam pelo conceito de violência simbólica de que trata Bourdieu:

(...) Sempre vi a dominação masculina, e no modo como é imposta e vivenciada, o exemplo por excelência desta submissão paradoxal, resultante daquilo que eu chamo de violência simbólica, violência suave, insensível, invisível a suas próprias vítimas, que se exerce essencialmente pelas vias puramente simbólicas da comunicação e do conhecimento, ou, mais precisamente do desconhecimento, do reconhecimento ou, em última instância, do sentimento. (BOURDIEU, 2003:09).

Para o efeito da violência simbólica, Bourdieu orienta que a adesão do dominado às estruturas de dominação é essencial, pois o sujeito passa a se avaliar segundo determinadas concepções. Dessa maneira a violência simbólica é incorporada e legitimada sob aparência da normalidade, ou ainda, "suave, insensível e invisível às suas próprias vítimas" (pág 09).

\section{3- O silenciamento.}

Em um diálogo, os sujeitos envolvidos buscam disciplinar o dizer para se aproximar de uma formação discursiva dada. Nessa passagem do processo de 
disciplinarização, caminha o silêncio em sua dimensão política, ou o silenciamento, que já foi definido com maiores detalhes por Eni Orlandi. Silencimento que na visão a autora não é "estar em silêncio”, mas "pôr em silêncio” (ORLANDI, 1995). É uma categoria que não estria apenas ligada à coação, mas é também, escolha. Dessa forma, podemos pensar que o silêncio é significado, na medida em que se relaciona com a história e a ideologia. Ele atua de forma a legitimar vozes e discursos ao mesmo tempo em que omite outros, sem deixar qualquer tipo de marca formal no discurso. Destacamos aqui a política do silêncio, que frisa que ao dizer o sujeito estará sempre não dizendo outros sentidos possíveis, já que as enunciações se dão sempre de um determinado local ideológico. A política do silêncio é ainda subdividida em duas outras categorias: o silêncio constitutivo, em que uma palavra apaga outras necessariamente, e o silêncio local relacionado à censura (ORLANDI 1995). Assim, compreender o silêncio é pensar na relação com o outro e nos remeter mais uma vez, à memória discursiva e à incorporação de comportamentos de que fala Bourdieu.

Pensando o silêncio como fruto da ideologia e da memória discursiva, é possível conjugar o silêncio com a difusão de imagens a partir dos Aparelhos Ideológicos de Estado (AIE'S) de que trata Louis Althusser (apud Zizek, 1996). A questão permite pensar que a condição da mulher negra se relaciona a estatutos de formação de identidade que a representam socialmente. Dessa forma, a construção de estereótipos pela mídia é uma das formas de manifestação do silenciamento. O filme, que confere um intercâmbio com a realidade, reproduz esse silêncio à medida que a construção da personagem Maria corresponde a determinados estereótipos: é pobre, negra, empregada doméstica, não tem estudo universitário, e ao se relacionar com um homem branco passa pelo conflito de não ser assumida por ele como esposa. Encontramos em Althusser (1970 apud ZIZEK 1996), uma importante contribuição teórica que contribui para a noção de silencimamento. O autor define que as classes dominantes possuem dois pólos que mecanizam a perpetuação das estruturas de dominação, sendo um deles os AIE ou Aparelhos Ideológicos de Estado, que se traduzem na figura institucional da escola, religião, cultura ou informação (ALTHUSSER 
1970 apud ZIZEK 1996). Para o autor, esses interviriam nos sujeitos através da difusão ideológica de maneira dissimulada, sendo, portanto um poder simbólico que oferece condições para a “incorporação da dominação”. Nessa postura, o cinema "atenua”, ou "obscurece" determinados processos históricos, de modo que as representações ali conformadas se encontrem dentro de uma determinada ordem. Essa ordem, como característica dos AIE, é muitas vezes atingida através do uso de elementos que estão disponíveis na cultura é que uma característica dos filmes realistas, como já dito no contexto da Retomada. O questionamento dessa dita aparência de real, que é construída através de estruturas que são encontradas no dia a dia dos sujeitos poderia parecer fora de contexto, pois são imagens aparentemente despretensiosas e fora de qualquer interesse político.

\section{4 -BENDITO FRUTO A PARTIR DE MARIA: LEITURAS POSSÍVEIS}

\footnotetext{
"Era vida em preto e branco, quase nunca colorida reprisando coisas que não fiz, finalmente se acabando feito longa, feito curta que termina com final feliz...". Xanéu nº5-O Teatro Mágico.
}

Em linhas gerais, o cotidiano que a trama contorna para a personagem mostra Maria como uma mulher, negra, pobre e empregada doméstica. De acordo com a historiadora Michelle Perrot, as mulheres sempre trabalharam. Suas atividades eram intimamente ligadas ao doméstico, portanto, era um trabalho que além de aparentar invisível e ausente de reconhecimento, nem sempre era remunerado. Nas palavras de Perrot: "O caráter doméstico marca todo o trabalho feminino: a mulher é sempre uma dona de casa. Isso se espera também da perfeita secretária: ela que coloque flores e que cuide de seu patrão" (PERROT, 2007; 114-15). Maria é uma doméstica, atividade comumente atribuída pela mídia às mulheres negras. A construção da história da personagem na mesma função de sua mãe, que também trabalhou para a família de 
Edgar $^{11}$, sugere um ponto de vista que perpetua e circunscreve o lugar da mulher pobre e negra a atividades ligadas ao braçal. A partir desse ponto, julga-se que a maneira como a personagem foi construída aponta para uma manutenção de estruturas tradicionais enraizadas no modelo casa-grande e senzala.

Quanto ao entorno da personagem, o filme retrata uma sociedade que assimila os comportamentos de uma determinada experiência dóxica; ou seja, aquela que "nos inclina tomar o mundo como dado" (BOURDIEU 2003: 18). Nesse sentido, a noção de memória discursiva é fundamental. Como exemplo, destaca-se o momento em que Maria vai enviar uma quantia em dinheiro para seu filho, que está na Espanha. Nesta cena, o operador de caixa que a atende diz para ela "pedir para a patroa preencher o formulário com letra de forma da próxima vez". Nesse sentido, vê-se que o funcionário não a questiona sobre sua profissão, mas afirma, através de sua fala, o papel do negro como servo, desprovido de um capital financeiro ou cultural. Vê-se que a personagem reproduz discursos que se relacionam a papéis pré-determinados em níveis superficiais de análise. Ainda nessa cena, Maria, apesar de perceber o julgamento do funcionário, também assimila uma parcela desse papel pré-determinado, quando apenas agradece e sai da agência.

No momento que antecede a sua entrada nos Correios, é focalizada a maneira como a doméstica se arruma: roupas chamativas e justas. No roteiro do filme, a descrição desse momento nos aponta para o estereótipo ${ }^{12}$ sobre o qual a personagem foi construída, que nesse caso, corresponde ao modelo da mulata sensual.

O foco central da produção está em torno das figuras do cabeleireiro e patrão de Maria, Edgar ${ }^{13}$, Maria, sua empregada doméstica e Virgínia ${ }^{14}$, antiga colega de classe do cabeleireiro, que retorna devido ao acidente com um bueiro que explode no início do filme.

\footnotetext{
${ }^{11}$ No filme, companheiro e patrão de Maria. Personagem interpretado por Otávio Augusto.

${ }^{12}$ Nesse estudo, entendemos o estereótipo como uma imagem pré-concebida sobre o sujeito ou um grupo de indivíduos.

${ }_{13}^{13}$ Personagem interpretado pelo ator Octavio Augusto.

${ }^{14}$ Personagem interpretada pela atriz Vera Holtz.
} 
O seu nome, “Maria”, utilizado sem nenhum complemento de sobrenome ou apelido, é ainda o nome que pode ser remetido ao lugar do "genérico", do popular presente em todas as camadas sociais nos trazendo a idéia desta "Maria" como um denominador comum. Retomemos o signo da casa-grande e da senzala para nossas considerações, em relação às raízes de um passado escravista, findado no século XIX, mas que mantém um legado simbólico na contemporaneidade através da memória discursiva: tem-se na película, uma Maria negra e sem sobrenome, empregada doméstica de jornada integral. Mora na casa do patrão, semelhantemente às escravas que eram determinadas a habitar a casa-grande, as amas de leite dos filhos da senhora ou as mucamas. O cabeleireiro, como à imagem do filho dos senhores das fazendas, é o herdeiro tanto da casa quanto do salão onde trabalha e se relaciona com Maria sem preocupação acerca do que ela poderia sentir na condição marginalizada em que ela se encontra no relacionamento. Segundo Michelle Perrot, a relação sexual entre o empregador e a empregada doméstica não é uma situação incomum no século XX. Nas palavras de PERROT (2007; 117), "além de seu tempo e de sua força de trabalho, sua pessoa e seu corpo (das domésticas) são requisitados, numa relação pessoal que ultrapassa o compromisso salarial”.

Os costumes da casa-grande, patriarcais, são também retomados através da figura do quadro localizado na parede da sala de jantar de Edgar. Retrato da mãe do cabeleireiro, presente em momentos em que a sala de jantar é filmada panoramicamente e, por vezes, nos discursos das personagens.

Em BARHTES (1984), tem-se que fotografia é capaz de repetir o que não mais poderá repetir-se existencialmente, de onde se pode inferir que, mesmo que a mãe do cabeleireiro não esteja presente naquele contexto, os costumes patriarcais agregados em sua figura passaram por um filtro cultural. O patriarcalismo também perpassa o relacionamento amoroso entre as personagens, uma vez que Edgar não tem por objetivo, a priori, assumir Maria como esposa. Da mesma forma, no período escravista, ainda que os senhores da casa grande mantivessem relações com suas escravas, estas nunca seriam assumidas perante a sociedade. Desse contexto histórico, 
surge a seguinte noção: Mulher negra é para trabalhar, mulata para fornicar e branca para casar. Vê-se então que na proposta de especularizar o cotidiano a que os filmes da fase do cinema da Retomada se propõem Bendito Fruto, ainda que não na forma de denúncia, demonstra a manutenção de uma escravidão simbólica a que as mulheres negras ainda são submetidas. Nas palavras de Helena Theodoro Lopes:

O mito da mulher negra supersexuada, construído ao longo da história, se origina da visão existente no período escravista que a considerava coisa, numa sociedade patriarcal, onde sempre predominou o poder do homem sobre a mulher (...) em função das limitações estabelecidas pela igreja em relação ao sexo no casamento, que seria apenas para procriação, a escrava era usada para satisfazer as necessidades sexuais dos senhores. Num contexto de valores morais e religiosos rígidos, vai recair sobre a negra a responsabilidade do desejo do senhor, que justifica seus atos como inevitáveis diante da intensa sensualidade da escrava, que fica à mercê dos senhores e de seus filhos, além de despertar o ciúme e a inveja da senhora, o que gera os mais bárbaros crimes de tortura e todo o tipo de violência contra as escravas no Brasil.

Para Eni Orlandi há uma relação entre silêncio e emoção no âmbito do discurso amoroso. Segundo a autora, "o discurso amoroso, em que a onipotência avizinha o impossível, é um discurso votado ao silêncio" (ORLANDI 1995: 43). E no caso de Maria isso se faz ainda mais forte. Desde pequena, ela nutre uma paixão não confessa por Edgar, como se percebesse uma barreira que os distanciasse. Há uma sequência de cenas que é capaz de traduzir esse pensamento: Edgar após consertar a imagem do aparelho de TV a pedido de Maria, ele se senta ao seu lado e ambos assistem a uma cena de telenovela. A câmera focaliza o diálogo entre um casal, no qual um homem diz á uma mulher que ela é "seu primeiro e único amor". A partir desse trecho, é feito um close no rosto de Maria, ao mesmo tempo em que entra uma trilha sonora internacional. Juntos, tais efeitos descrevem o sentimento afetivo da doméstica por Edgar, e acionam sua memória para a infância. $O$ trecho sugere um momento em que Maria transgride o silêncio, ainda que timidamente e somente para si, quando relembra que escreveu no encarte de um disco da patroa de sua mãe "Maria ama Edgar". 
Para Perrot, a correspondência, a autobiografia e o diário íntimo seriam gêneros textuais tipicamente femininos. Seriam, portanto, escritos precisos para a intimidade feminina por autorizarem a "afirmação de um 'eu"” (PERROT, 2007: 30), textos privados em que a mulher conta sua vida, uma vez que o lugar subalterno de onde ela fala silencia o diálogo na realidade. Ainda nas palavras de PERROT (2007: 29): "Forma distanciada do amor, mais conveniente e menos perigosa do que o encontro, a carta de amor toma o lugar do próprio amor, a ponto de representar o essencial". Completando essa seqüência de cenas, a câmera focaliza objetos antigos, através do travelling por um quarto no qual Maria se encontra. Dentre esses objetos, há o destaque para um vestido de noiva que pertenceu à mãe do cabeleireiro. Nessa cena, o vestido é um motivador do qual Maria se utiliza para sugerir sua intenção de se casar com Edgar, assunto do qual ele desvia.

Para a criação do clímax da produção, é incorporada a figura da personagem Virgínia, cuja presença retoma o nome do filme. Branca, viúva, ex-colega de escola do cabeleireiro, a personagem adentra o espaço da casa, fazendo com que o relacionamento entre ela e Maria ocorra de maneira menos amistosa. Quando Virgínia chega, Maria assume de maneira literal o lugar da prestadora de serviços do lar, aquela que não adentra os assuntos particulares dos donos da casa. Nessa cena, o cabeleireiro também assume o seu papel social de patrão sempre que se dirige à doméstica, através de perguntas como “o almoço já tá pronto?”. Completando o quadro das representações, Maria que habitualmente se sentava à mesa junto de Edgar durante as refeições, almoça na cozinha, em pé, sem que tal atitude fosse um pedido formal por parte do cabeleireiro, como se ambos cumprissem as premissas de um contrato e assumissem "seus lugares" no campo das relações. Uma trilha sonora acompanha a doméstica nesse momento, traduzindo o que não é dito por meio de palavras: "Você me deixou sem olhar pra trás, sem nenhum motivo, mas agora tanto faz. Você me deixou, solto no abandono, no meio da rua feito um cão sem dono...". O ponto de vista da câmera, um close no rosto da personagem seguido de um plongé, tomada de cima para baixo fazendo com que o espectador veja a cena verticalmente, abre ângulo de 
filmagem e inclui o cachorro que está no mesmo recinto. São efeitos capazes de centralizar a situação psicológica de pequenez e abandono que tomam o lugar da fala da personagem, silenciada diante da situação em que se encontra. Segundo ORLANDI (1995), a música propõe uma relação com o silêncio, como se ela traduzisse os sentimentos inconfessáveis para a situação.

No desenrolar da trama, Maria volta para a sua casa. A residência da doméstica ganha menor destaque no filme e se localiza na periferia carioca: uma casa pequena, ausente de qualquer luxo, em que se faz possível uma analogia com senzala, que era localizada a uma certa distância da casa-grande. No momento em que Edgar a procura Maria para pedir sua volta para casa, podemos perceber o momento em que a personagem tenta quebrar com o silêncio, retomando a memória que o sustenta, resgatando imaginários construídos discursivamente sobre a mulher negra para construir sua argumentação. A situação demonstra o que já defendia Bourdieu, quando nos diz que a perpetuação da dominação implica em um determinado conhecimento dessa situação por parte dos dominados. O silêncio nesse momento se manifesta pela ausência de resposta por parte de Edgar, que retorna para casa, sem dizer nada.

\section{- Silenciamento da mulher negra e a pertuação de locais de PERTENCIMENTO: PODERIAMOS FALAR EM CONSIDERAÇÕES FINAIS?}

A elaboração deste artigo foi fruto da necessidade de se pensar relações de gênero atreladas às temáticas raciais, assuntos ainda pouco discutidos nos círculos acadêmicos. Ao se analisar a posição da mulher negra, vê-se que este lugar ainda é permeado pelo estigma da escravidão, tanto nas suas próprias atitudes quanto nas atitudes dos sujeitos ao seu redor. Atitudes essas que são reforçadas ou refutadas por diversos veículos, sendo um deles as representações feitas pela mídia. Guareschi (2004) afirma que o poder da comunicação pode criar realidades ou fazer com que elas 
desapareçam na medida em que são silenciadas. Realidades que em relação à mulher negra se traduzem pela representação estigmatizada de discursos, que por conseqüência, afetam a maneira como essas mulheres atuam na sociedade.

Na figura dessa mulher, sobretudo, recai a memória da escravidão, da mulata detentora de uma sexualidade exacerbada destinada ao trabalho braçal. Nesse sentido, a escolha por Bendito Fruto para o percurso teórico proposto, filme do contexto do Cinema da Retomada e que objetiva a apreciação de um grande público, se justifica. A Obra apresenta imagens estas que, através da memória discursiva, julga-se ter raízes no período da escravidão, momento em que os negros eram considerados "coisas", destinados a servidão. Discursos de raízes na ideologia do branqueamento da virada do século XIX, que sobrepôs simbolicamente o padrão branco como modelo a ser seguido, causando a diluição do ethos afro-descendente da população negra do país, como consequência. Em relação ao percurso teórico traçado através da A.D, encontrou-se, por meio da naturalização de determinados discursos sobre a mulher negra, as raízes de seu silenciamanto na contemporaneidade o qual tem na materialidade cinematográfica, vista aqui enquanto um Aparelho Ideológico de Estado, um dos meios para sua legitimação. Nesse sentido, a estereotipia através da qual Maria é construída, doméstica que serve aos apetites sexuais do patrão que não a assume perante a sociedade, é trabalho de uma memória discursiva orientada na manutenção de posições de poder. Por se mostrar de cunho realista, estratégia que também se deflagra através de enquadramentos que parecem mostrar uma câmera silenciosa no campo das opiniões, a película busca elementos acolhidos pela cultura para sua aceitação, demonstrando, dessa forma, jogos ideológicos que perpetuam uma determinada hegemonia hierárquica simbólica através de raça, gênero e cultura sob do véu do, do "natural".

Durante todo o enredo do filme, fez-se notável a presença da telenovela no cotidiano das personagens e a relação deste elemento nas atitudes dos mesmos. 0 filme então segue semelhante ao padrão da teledramaturgia nacional, não só pela câmera ou pelos enquadramentos, mas também através dos discursos resgatados. 
Apesar abordar uma protagonista negra, a representação oferecida por meio dela a mantém em arquétipos não orientados no sentido de trazer essas mulheres a outras posições. Na mesma linha, a trajetória de Maria completa esse enredo teledramatúrgico: a personagem tem um percurso marcado por sofrimentos que no final passam por uma catarse, um final feliz que remedia todos os problemas anteriores, podendo excluir possibilidades de crítica. Assim, ao escolher o cinema para o percurso do silenciamento em relação à mulher negra, este texto objetivou deslocar o filme de uma função que passa em primeira análise pelo entretenimento despretensioso, para então apontar como produções potencialmente dotadas de uma reflexão crítica devido às temáticas que aborda, acabar sendo articulado dentro de limites consentidos ideologicamente. Buscou-se, portanto, um intercâmbio com a sociedade, uma vez que nesse meio se encontram principais consumidores e propagadores das atitudes transmitidas pela obra. Por este texto se tratar de um recorte tão pequeno de um assunto ainda tão presente quanto extenso, permanece o questionamento: poderíamos pensar em considerações finais?

\section{8- REFERÊNCIAS}

BARTHES, Roland. A câmara clara: nota sobre a fotografia. Rio de Janeiro:Ed Nova Fronteira, 1984.

BERGER, Petet L; Luckman, Thomas. A realidade da vida cotidiana. In: A constrição social da realidade. Vozes, Petrópolis, 2005, $25^{\text {a ed. }}$

BOURDIEU, Pierre. A dominação masculina. $3^{\text {a }}$ ed. Rio de Janeiro, Bertrand Brasil, 2003. O Poder Simbólico. Rio de Janeiro, 1989, ed. Bertrand.

BRANDÃO, Helena H. Nagamine. Introdução á Análise do Discurso. $3^{\mathrm{a}}$ ed. Campinas, SP, 2007. Ed. Unicamp.

ORLANDI, Eni Puccinelli. As Formas do Silêncio. $3^{\text {a }}$ ed. Campinas, SP. UNICAMP, 1995. 
PERROT, Michelle.Minha história das mulheres. São Paulo: Contexto, 2007.

PRYSTHON, Ângela. O subalterno na tela: um novo cânone para o cinema brasileiro? In: XIII Encontro Anual da COMPÓS, 2004, São Bernardo do Campo, p.1-13.

SILVA, Tomaz Tadeu da. (org). Identidade e Diferença. Ed. Vozes, Petrópolis, 200.

TURNER, Turner. Cinema como Prática Social. Ed. Summus editorial Itda - São Paulo - SP -1988 .

ZIZEK, Slavoj (org.). Um Mapa da Ideologia. $1^{\text {a }}$ ed. Rio de Janeiro, Ed. Contraponto. 